\title{
Contagion and Optimization in Financial Markets
}

\author{
Jerome L. Stein ${ }^{*}$ \\ Division of Applied Mathematics, Box F, Brown University, Providence, RI 02912, USA

\begin{abstract}
The US financial crisis of 2008 involved the interaction of banks and security houses. The issues of "contagion" and debt crises became subjects of concern. The aim of this paper is to suggest dynamic nonlinear models of the interactions and optimization in financial markets, which explain the dynamics of contagion and the vulnerability of the financial sector to shocks. I compare stochastic and deterministic models of "optimal" debt. In each case an early warning signal of financial difficulties is an "excessive" debt ratio equal to the actual less the derived optimal ratio.
\end{abstract}

Keywords: Contagion, differential game, dynamic nonlinear models, financial markets, stochastic optimal control.

\section{LEVERAGE AND LINKAGES IN THE FINANCIAL MARKETS}

The US financial crisis of 2008 involved the interaction of banks and security houses. The issues of "contagion" and debt crises became subjects of concern. The aim of this paper is to suggest dynamic nonlinear models of the interactions and optimization in financial markets, which explain the dynamics of contagion and the vulnerability of the financial sector to shocks. I compare stochastic and deterministic models of "optimal" debt.

Richard Feynman [1] compared mathematics with physics. "Mathematicians are only dealing with the structure of reasoning, and they do not really care what they are talking about.... In other words, mathematicians prepare abstract reasoning ready to be used if you have a set of axioms about the real world. But the physicist has meaning to all his phrases. That is a very important thing that a lot of people who come to physics by way of mathematics do not appreciate. Physics is not mathematics and mathematics is not physics...in physics you have to have an understanding of the connection of words with the real world."

The "Quants" are a group of physicists, computer scientists and mathematicians who practice "financial engineering" in Wall Street. See Derman [2]. Substitute "economics, finance" for physics and one will better understand the errors of the "Quants" in the financial crisis of 2008; see Stein [3]. They assumed that physics could be the key to operating in financial markets, without understanding the economics of these markets.

The housing price bubble, defined as a non-sustainable growth in prices, in the US led to the growth of household debt. A bubble is dangerous insofar as it induces a nonsustainable debt. This danger is exacerbated insofar as a complex financial system is based upon it. The theme of Stein [3] is that the application of Stochastic Optimal

*Address correspondence to this author at the Division of Applied Mathematics, Box F, Brown University, Providence, RI 02912, USA;

Tel: (401) 272-6015; Fax: (401) 863-1355;

E-mail: Jerome_Stein@Brown.edu
Control (SOC) is very helpful in understanding and predicting the financial debt crisis of 2008, the crises of the 1980 s and an analysis of the European debt crisis. I use SOC to derive a theoretically founded quantitative measure of an optimal, and an excessive leverage/ debt/ risk that increases the probability of a crisis. The optimal leverage - defined as $1+\mathrm{debt} /$ net worth - balances risk against expected growth. The environment is stochastic: the capital gain, productivity of capital and interest rate are stochastic variables.

In the current paper, I discuss how nonlinear dynamic models are useful in understanding the financial crisis. Several topics are discussed: (i) the interaction of securities firms and the shadow banking system leading to contagion, (ii) stochastic and deterministic approaches to evaluating the optimal debt of the financial sector, with an aim to derive early warning signals of a crisis.

In part 1, I sketch the US financial crisis and the interactions among the debtors and creditors. Thereby the reader has the empirical background in mind to evaluate the subsequent mathematical modeling. In part 2 , I present a nonlinear model of contagion between financial institutions. Parts 3 and 4 are concerned with the optimal and excessive debt of the financial sector, where an excessive debt increases the probability of a debt crisis. The stochastic and deterministic approaches are contrasted. Part 3 concerns a stochastic environment, and the aim is to derive early warning signals of a crisis. In the stochastic approach, the criterion is the maximization of the expectation of the logarithm of net worth, subject to stochastic processes involving Brownian Motion (BM) diffusion terms. An alternative approach, taken in part 4 , involves a differential game against Nature. The objective is to maximize the minimum expected growth of net worth. This is a risk averse strategy. No stochastic processes are involved. I contrast the implications of the two approaches.

\subsection{US Financial Crisis}

A sketch of the linkages in the financial system shows how contagion occurs. The securitization firms and investment banks financed their purchases of mortgages by borrowing from the money market mutual funds, the shadow banking system. Whereas banks traditionally took money 
from deposits to make loans and held them to maturity, the investment banks used money from the capital market, often from Money Market Mutual Funds, to make loans, package them into securities - securitization - to sell to investors.

The financial crisis was precipitated by the mortgage crisis. First, a whole structure of financial derivatives securities whose values were ultimately derived from the mortgages - was based upon the ultimate debtors: the mortgagors. Insofar as the mortgagors were unable to service their debts, the values of the derivatives fell. Second, the financial intermediaries whose assets and liabilities were based upon the value of derivatives were very highly leveraged. Changes in the values of their net worth were large multiples of changes in asset values. Third, the financial intermediaries were closely linked - the assets of one group were liabilities of another. A cascade was precipitated by the mortgage defaults. Since the "Quants" were following the same rules, the markets would not be liquid.

Define infection as a situation where the firm becomes insolvent (assets are less than liabilities), or that the firm is illiquid/does not have marketable assets or collateral to satisfy its creditors. When the mortgagors could not repay their debts, the investment banks/security firms were infected. In turn they could not repay their debts to the shadow banking system. In turn, as the net worth of the shadow banking system declined, they were infected and they were more reluctant to lend/finance the activities of the security firms. They demanded more and better collateral from the securities firms. This infected the latter. Contagion occurs when each group infects the other.

\section{A DYNAMIC NONLINEAR DETERMINISTIC MODEL OF CONTAGION}

Infection consists of either insolvency or serious liquidity problems. The aim in this part is to examine the contagion whereby one group infects the other. What will be the equilibrium/equilibria $\left(\mathrm{x}^{*}, \mathrm{y}^{*}\right)$ of infection of the groups? What will be the trajectories to the equilibrium? My model is inspired by the mathematical biology literature. See Handel et al. [4], Stewart and Levin [5], Frank [6] and Braun [7] for modeling references.

Let there be two sets of financial institutions whose total numbers are $\mathrm{B}>0$ and $\mathrm{S}>0$. They could be $\mathrm{B}=$ banks, $\mathrm{S}=$ security houses as in the US financial crisis. Each holds assets in the other or has liabilities to the other.

The nonlinear model is described by equations (1) and (2). The state variables are $x(t)$ the infected in set $B$ and $y(t)$ the infected in set $\mathrm{S}$. The non-infected group is called "susceptible". Thus $[\mathrm{B}-\mathrm{x}(\mathrm{t})]$ are susceptible in set $\mathrm{B}$ and $[\mathrm{S}$ $-y(t)]$ are the susceptible in set $S$.

Contagion occurs when the susceptible of one group is in contact with the infected of the other group. Box 1 summarizes the framework. For example, financial institutions borrow short term from the Shadow Banking System and lend longer term to Securities houses - who buy longer term debt. If the securities houses are infected, cannot repay the banks or have liquidity problems, then the banks become infected - they have liquidity or solvency problems. Similarly, if the banks are infected, then funds to the securities firms are not available and the securities firms are infected. The infections go both ways: debtor and creditor.

\section{Box 1. Model of Contagion}

\begin{tabular}{|c|c|c|}
\hline Number B & $\mathrm{S}$ & \\
\hline Infected $x(t)$ & $y(t)$ & \\
\hline Susceptible & $\mathrm{S}-\mathrm{y}(\mathrm{t})$ & \\
\hline Contacts $[\mathrm{B}-\mathrm{x}(\mathrm{t})] \mathrm{y}(\mathrm{t})$ & {$[S-y(t)] x(t)$} & \\
\hline$d x(t) / d t=-a_{1} x(t)+b_{1}(B$ & $-x(t)) y(t) \ldots$ & (1) \\
\hline$d y(t) / d t=-a_{2} y(t)+b_{2}(S-$ & $y(t)) x(t) \ldots$ & (2) \\
\hline$b_{i}>0=$ infection rate & $a_{i}>0=$ recovery rate & $\mathrm{i}=1,2$ \\
\hline
\end{tabular}

The first term in equation (1) states that infection in set B will decrease as the infected recover at rate $\mathrm{a}_{1} \mathrm{x}(\mathrm{t})$, where the recovery may consist of some inflow of capital from an external source. For example, if it is a liquidity problem not a solvency problem - the banks borrow from the central bank to tide them over. Alternatively, they obtain more capital by issuing stock. The second term is the infection. Susceptible banks $(B-x(t))$ which have financial relations with $y(t)$ infected security houses $S$ are infected at rate $b_{1}(B$ $-x(t)) y(t)$. This is contagion from $S$ to B. For example, set B consists of creditors of set $\mathrm{S}$. If $\mathrm{S}$ cannot pay their debts, then set B becomes "infected".

Equation (2) is the corresponding situation for set $\mathrm{S}$. Equation (2) states that infection in set $S$ will decrease as the infected recover at rate $\mathrm{a}_{2} \mathrm{y}(\mathrm{t})$, where the recovery consists of some inflow of capital from an external source. However, the susceptible securities firms $(\mathrm{S}-\mathrm{y}(\mathrm{t}))$ which meet $\mathrm{x}(\mathrm{t})$ infected banks $B$ are infected at rate $b_{2}(S-y(t)) x(t)$. This is contagion from B to $\mathrm{S}$. Thus equations (1) and (2) are the nonlinear dynamics of infection from one group to another.

There are two equilibria - denoted by an asterisk - where $\mathrm{dx} / \mathrm{dt}=0$ and $\mathrm{dy} / \mathrm{dt}=0$. The equilibrium conditions $(1 \mathrm{a})$ and (2a) are that, for each group, the recovery rate is equal to the rate of new infection.

$\mathrm{a}_{1} \mathrm{x}^{*}=\mathrm{b}_{1}\left(\mathrm{~B}-\mathrm{x}^{*}\right) \mathrm{y}^{*} \ldots$

$a_{2} y^{*}=b_{2}\left(S-y^{*}\right) x^{*} \ldots$

One equilibrium is $\mathrm{x}^{*}=0$ and $\mathrm{y}^{*}=0$. The second is described by equations (3) and (4) where $x^{*}>0, y^{*}>0$. This condition requires that the product of the two infection rates $b_{1} b_{2} B S$ exceed the product $a_{1} a_{2}$ of the recovery rates. These two equilbria correspond to different periods of financial stress, described in Fig. (1). The financial stress index is a composite index developed by the Federal Reserve Bank of St. Louis. The period of high financial stress is $2008-09$, where the equilibrium is equations (3),(4). The periods of low financial stress are those where the equilibrium is $\left(\mathrm{x}^{*}, \mathrm{y}^{*}\right)=0$.

Consider the periods of high financial stress. For $\mathrm{x}^{*}>0$, $y^{*}>0$, require that $\left(b_{1} b_{2} B S-a_{1} a_{2}\right)>0$, equations (3),(4).

$x^{*}=\left(b_{1} b_{2} B S-a_{1} a_{2}\right) /\left(a_{1} b_{2}+b_{1} b_{2} S\right)>0 \ldots$

$y^{*}=\left(b_{1} b_{2} B S-a_{1} a_{2}\right) /\left(a_{2} b_{1}+b_{1} b_{2} B\right)>0 \ldots$

The nonlinear dynamics of the model, equations (1)-(4), is described by phase diagram Fig. (2). The method of using 


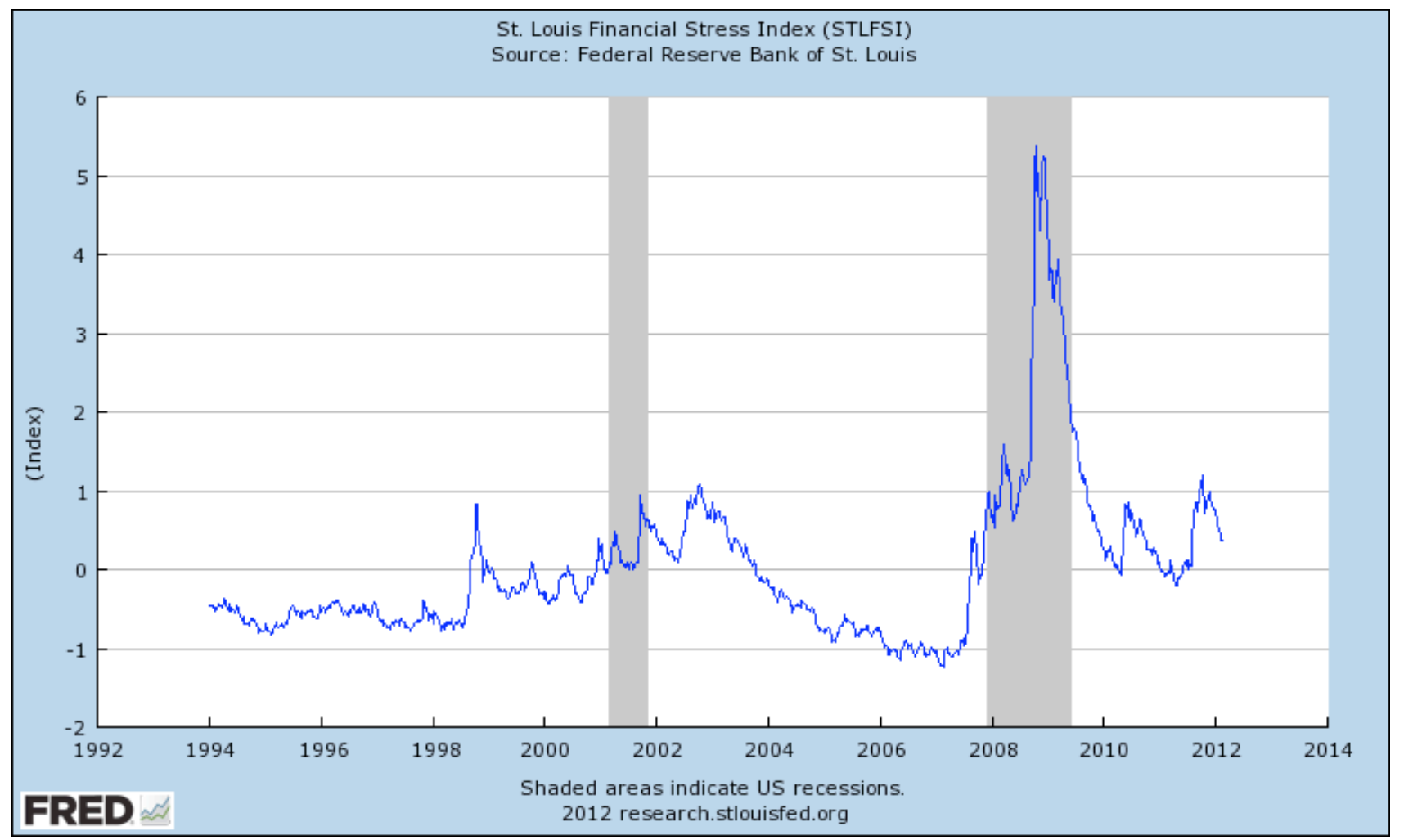

Fig. (1). Financial Stress Index.

phase diagrams, to derive qualitative solutions of the dynamics, is explained in [7]. Equations (5), (6) describe the locus of equilibrium points $(x, y)>0$. From $(5),(6),(1),(2)$ I derive the trajectories in Fig. (2). This is precisely the method of phase diagrams.

The relation between $[\mathrm{x}, \mathrm{y}]$, such that in equation (1), $d x(t) / d t=-a_{1} x(t)+b_{1}(B-x(t)) y(t)=0$, is equation (5). This equation is independent of time.

$y(x)=a_{1} x / b_{1}(B-x)=F(x) \mid d x(t) / d t=0 \ldots$

$\mathrm{F}(\mathrm{x})$ is graphed in Fig. (2). This is the locus of equilibrium points $x$, for given vales of $y$. Along $\mathrm{F}(\mathrm{x})$, the value of $\mathrm{dx} / \mathrm{dt}=0$. It is highly convex and goes from $\mathrm{F}(0)=$ 0 to $F(B)=+\infty$. When $y$ is above the curve $F(x)$ then $d x(t) / d t$ $>0$ and when $y(t)$ is below the curve $F(x)$, then $d x(t) / d t<0$. The horizontal vectors indicate the direction of motion, summarized below.

The relation between $[\mathrm{x}, \mathrm{y}]$, such that in equation (2), $\mathrm{dy}(\mathrm{t}) / \mathrm{dt}=-\mathrm{a}_{2} \mathrm{y}(\mathrm{t})+\mathrm{b}_{2}(\mathrm{~S}-\mathrm{y}(\mathrm{t})) \mathrm{x}(\mathrm{t})=0$ is equation (6). This is the locus of equilibrium points $y$ for given values of $x$. This equation is independent of time.

$y(x)=b_{2} S x /\left(a_{2}+b_{2} x(t)\right)=G(x) \mid d y(t) / d t=0 \ldots$

This is a concave function where $\mathrm{y}(\mathrm{x})$ runs from $\mathrm{y}=0$ to $y=S$. When $y>G(x)$ then $d y / d t<0$, and when $y<G(x(t))$ then $\mathrm{dy} / \mathrm{dt}>0$. The vertical vectors describe the dynamics, summarized below.

Table 1 summarizes the phase diagrams Figs. $(\mathbf{2}, \mathbf{3})$.

In periods of high financial stress, the slope of the $G(x)$ function exceeds that of the $\mathrm{F}(\mathrm{x})$ function at $\mathrm{x}=0$ if (7) or (7a) is satisfied. This condition is precisely the condition that $\left(x^{*}, y^{*}\right)$ be positive - equations (3) and (4).

$\left(\mathrm{x}^{*}, \mathrm{y}^{*}\right)>0$, high financial stress if:

$G^{\prime}(0)>F^{\prime}(0)$ if $b_{2} S / a_{2}>a_{1} / b_{1} B$ or $\ldots$

$b_{1} b_{2} B S>a_{1} a_{2}$. ...

The phase diagram in Fig. (2) has been drawn such that the equilibrium values are positive. The vectors describe the trajectories to the equilibrium. For example, if set $\mathrm{S}$ is infected what will be the magnitude of the infection of set $\mathrm{B}$ ? Points $\mathrm{P}(0), \mathrm{P}(1)$ and $\mathrm{P}(2)$ are arbitrary initial conditions.

Table 1. Summary of Trajectories in Phase Diagrams

\begin{tabular}{|c|c|c|}
\hline$d x(t) / d t=0, y=F(x)$ & $y>F(x)=>d x / d t>0$ & $y<F(x)=>d x / d t<0$ \\
\hline$d y / d t=0, y=G(x)$ & $y>G(x)=>d y / d t<0$ & $y<G(x)=>d y / d t>0$ \\
\hline
\end{tabular}

Start Fig. (2) at $\mathrm{P}(0)$ where securities houses are infected but not as yet the banks. Initially, the securities houses will start to recover, but they now begin to infect the banks. The trajectory leads to point $\mathrm{P}(1)$ in the region between the two curves where both are infected. If we are now at $\mathrm{P}(1)$ the trajectory to the equilibrium $x^{*}, y^{*}$ is described by the curve from $\mathrm{P}(1)$ to $\mathrm{P}(2)$ and then to point $\left(\mathrm{x}^{*}, \mathrm{y}^{*}\right)$. Every solution of equations (1)-(4) with $(x(0), y(0))>0$ will approach the solution $\mathrm{x}^{*}, \mathrm{y}^{*}$. Thus if we start with a low level of infection $\mathrm{P}(1)$, infection rates of both the sets $\mathrm{B}$ and the $\mathrm{S}$ will increase and reach an equilibrium $\left(\mathrm{x}^{*}, \mathrm{y}^{*}\right)>0$. In the figure the equilibrium infection is incomplete, $\mathrm{x}^{*}<\mathrm{B}$ and $\mathrm{y}^{*}<\mathrm{S}$. 
The only way to reduce the infection of set $\mathrm{B}$, arising from infection of set $S$, is to reduce $x^{*}$ in equation (3). This can be done in several ways. First, if the infection is due to liquidity/collateral problems, where the firms in $S$ are solvent, but do not have sufficient collateral, one can increase the recovery rates $a_{i}$ by temporary borrowing from outside sources such as the central bank. Second, the infection rates $b_{i}$ must be reduced. A high leverage means that a percent change in asset values produces a large percentage change in net worth. A lowering of the infection rate involves an increase in the capital requirement or a decline in leverage such that a decline in asset values does not seriously reduce net worth.

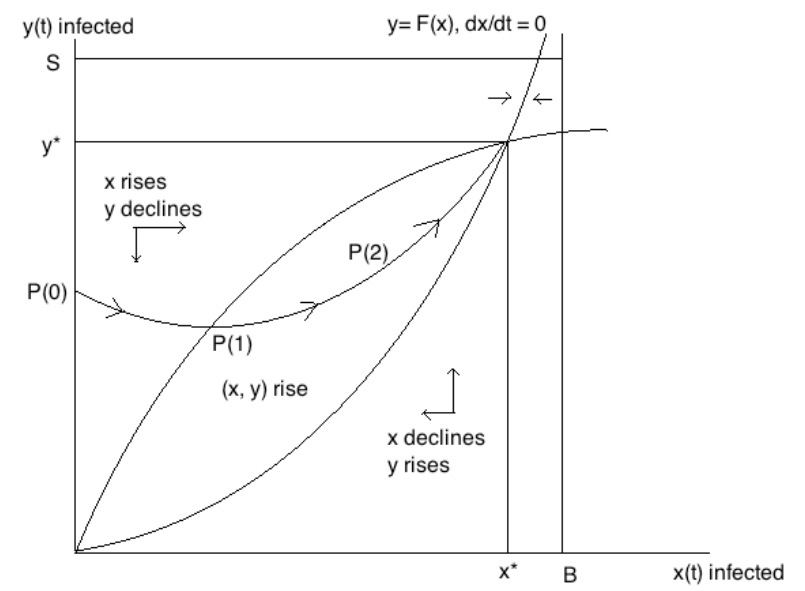

Fig. (2). High financial stress periods:Trajectories to a positive equilibrium infection $\left(x^{*}, y^{*}\right)>0$. Along curve $y=F(x) \mid d x / d t=0$ and $x(t)$ moves towards the F curve. Along $y=G(x) \mid d y / d t=0$ and $y(t)$ moves to the $G$ curve. The infection rates move ultimately into the region between the two curves.

In this case, where the infection rates $b_{i}(1)$ exceed the recovery rates $a_{i}(1)$, equations $(3)(4)$, the economy moves to an equilibrium $\left(\mathrm{x}^{*}, \mathrm{y}^{*}\right)>0$ where both sectors are infected. However, the values of the infection rates depend upon the state of the economy: is there a financial crisis?

If the financial markets are tranquil - then the infection rates are low and recovery rates are high. In such periods where there are low values of the financial stress index (Fig. 1), the infection rates converge to the origin. This is Fig. (3). Formally, $b_{i}(2)$ is less than the recovery rates $a_{i}(2)$. Phase diagram Fig. (3) graphs the dynamics of the infection rates. This means that the economy converges to an equilibrium $\left(\mathrm{x}^{*}(2), \mathrm{y}^{*}(2)\right)=0$.

\section{ANALYSIS OF DEBT CRISES: A COMPARISON OF STOCHASTIC AND DETERMINISTIC APPRO- ACHES TO OPTIMAL DEBT}

Recall that the financial crisis was precipitated by the mortgage crisis. First, a whole structure of financial derivatives - securities whose values were ultimately derived from the mortgages - was based upon the ultimate debtors: the mortgagors. Insofar as the mortgagors were unable to service their debts, the values of the derivatives fell. Second, the financial intermediaries whose assets and liabilities were based upon the value of derivatives were very highly leveraged. Changes in the values of their net worth were large multiples of changes in asset values. Third, the financial intermediaries were closely linked - the assets of one group were liabilities of another. A cascade was precipitated by the mortgage defaults. When the mortgagors could not repay their debts, the investment banks/security firms were infected. In turn they could not repay their debts to the shadow banking system. In turn, as the net worth of the shadow banking system declined, they were infected and they were more reluctant to lend/finance the activities of the security firms. They demanded more and better collateral from the securities firms. This infected the latter.

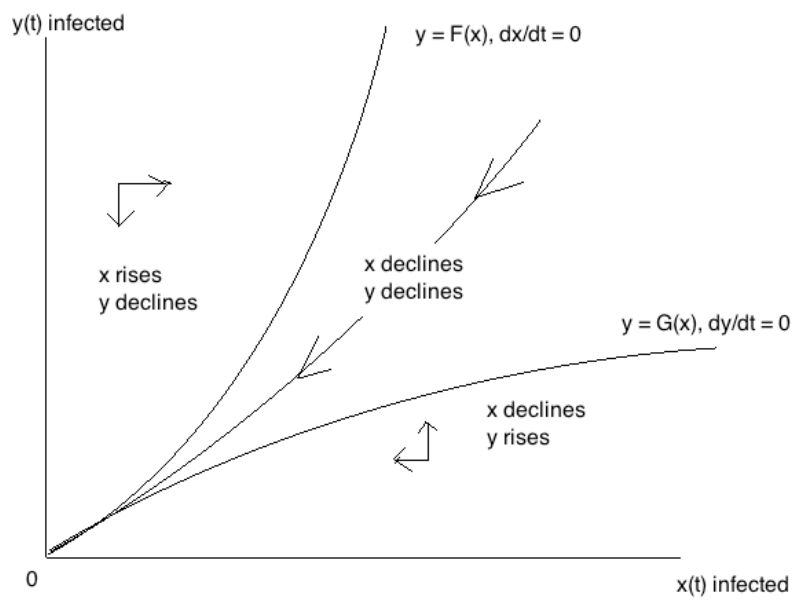

Fig. (3). Trajectory to equilibrium $\left(x^{*}(2), y^{*}(2)\right)=0$ from crisis equilibrium $\left(\mathrm{x}^{*}, \mathrm{y}^{*}\right)$.

The crucial question is: What is an optimal debt of the housing sector - the mortgagors and the financial intermediaries? Stein [3] showed that "too little" debt decreases the growth of the economy and "too much" debt increases the probability of bankruptcy, illiquidity - an inability to repay. The latter situation led to the financial crisis of 2008 described in part 1.

The aim of this and the following sections is to compare two approaches: stochastic and deterministic in evaluating the optimum debt. Section 3 presupposes that the reader is familiar with the stochastic calculus and Ito equation. This approach is at the core of the mathematical finance literature. Basic references are Øksendal [8], Merton [9] and Fleming and Rishel [10], Fleming and Soner [11], Stein [12].

The questions are: what is an optimal debt, what is an excessive debt that would lead to a debt crisis? The Stochastic Optimal Control (SOC) analysis is based upon stochastic processes that have drifts and Markov diffusions. The diffusions are Brownian Motion (BM). Thus the disturbances are assumed to be normal and i.i.d. The techniques of analysis are either the Ito equation or dynamic programming.

Since the BM assumptions are highly questionable as descriptions of stochastic processes, an alternative approach is to view the optimization process as a deterministic differential game against Nature. The "player" - firm, industry, country - selects a debt. Nature is the stronger player. Knowing the debt chosen, she selects a disturbance that minimizes the expectation of the growth of net worth. The player then selects a debt ratio that maximizes the 
minimum of the expectation of the growth of net worth. This is a highly risk averse strategy. We then have the "optimum" debt ratio, which maximizes the expectation of the minimum growth of net worth. I conclude by comparing the implications of the two approaches, summarized in Table 2.

\subsection{The Stochastic Optimal Control Analysis}

The objective function is the maximization of the expected logarithm of net worth. The hypothetical maximizer is the housing sector: the mortgagors and related financial intermediaries. The mathematical analysis in this part is based upon Stein [3,12] and Fleming and Stein [13], which contain the full details. Here, I present a terse sketch of the results.

Net worth is assets less liabilities, equation (8). The percent change, growth, in net worth is equation (9).

Net worth $=$ assets - debt .

Growth of net worth $=($ assets $/$ net worth) $($ capital gain + return on assets) - (debt/net worth)(interest rate) - consumption/net worth.

Leverage is defined as assets/net worth. Leverage and debt will be used interchangeably. The ratio of assets/net worth $=$ leverage $=1+\operatorname{debt} /$ net worth, from (8).

Denote $X(t)=$ net worth, $f(t)=$ debt/net worth, $b(t)=$ (capital gain + return on assets) and $c=$ arbitrary constant consumption/net worth. The interest rate is $r(t)$. Refer to $b(t)$ as the return on investment. Thus equation (9) is (10). The only control variable is the debt ratio or equivalently leverage. The uncertainty concerns the terms in $b(t)=$ (capital gain + return on assets), the interest rate $\mathrm{r}(\mathrm{t})$.

$d X(t)=X(t)[(1+f(t)) b(t)-r(t) f(t)-c] d t$

The growth of net worth depends upon leverage or the debt ratio, equation $(9) /(10)$. The growth is increased by $b(t)$ the return on investment, but decreased by the associated interest payments. The return on investment has two components: the return on assets and the capital gain on the assets. For example, if the assets were housing then the return on assets is rental income/assets and the capital gain is the appreciation of the price of housing.

Therefore, an increase in leverage or debt will increase expected growth of net worth if the return on investment exceeds the interest rate, $b(t)>r(t)$. The productivity of assets is observed, but the future capital gain and the interest rates are unknown when the investment decision is made.

The return $b(t)$ and interest rate $r(t)$ as assumed to follow stochastic processes (11) and (12). This is the world of mathematical finance, where the stochastic calculus and Ito equation are essential tools. See $[3,8-10,13]$. The reader who is not familiar with this literature should go directly to the discussion around Fig. (4).

The stochastic processes are described by equations (11) and (12). Each equation has two components on the right hand side: a drift and a diffusion. The first is the mean and the second part contains a Brownian Motion term, with a zero mean and variance proportional to $\mathrm{dt}$.

$b(t) d t=b d t+\sigma_{y} d w_{y}$
$r(t) d t=r d t+\sigma_{r} d w_{r}$
Equation (11) states that the return on investment is the sum of two elements. The first is a deterministic $b d t$. The second element is a stochastic term $\sigma_{\mathrm{y}} \mathrm{dw}_{\mathrm{y}}$ where $\mathrm{E}\left(\mathrm{dw}_{\mathrm{y}}\right)=0$, $\mathrm{E}\left(\mathrm{dw}_{\mathrm{y}}{ }^{2}\right)=\mathrm{dt}$. Equation (12) states that the interest rate $\mathrm{r}(\mathrm{t})$ is the sum of a deterministic term $r$ dt plus a stochastic term $\mathrm{dw}_{\mathrm{r}}$, where $\mathrm{E}\left(\mathrm{dw}_{\mathrm{r}}\right)=0, \mathrm{E}\left(\mathrm{dw}_{\mathrm{r}}^{2}\right)=\mathrm{dt}$.

\subsection{Solution of the Model}

The objective is to select a ratio of debt/net worth or leverage assets/net worth to maximize the expectation of the logarithm of net worth at some later date, subject to the constraints on the stochastic variables. This is a special case of the HARA utility function in the finance literature. The advantages of using the logarithmic function are discussed in [3, ch. 4]. Using equations (10)-(12), the change in net worth equation (10) is stochastic differential equation (13). Control variable $f(t)$ is the debt/net worth ratio. The first set of terms is deterministic and the second set are stochastic.

$d X(t)=[(b-c)+(b-r) f(t)] X(t) d t+\left[\sigma_{y}(1+f(t)) d w_{y}-\sigma_{r} f(t)\right.$ $\left.d w_{r}\right] X(t) \ldots$

The first set states that net worth will grow if $(b-c)>0$ the productivity of capital $b$ exceeds the arbitrarily constant ratio $\mathrm{c}=\mathrm{C}(\mathrm{t}) / \mathrm{X}(\mathrm{t})$ of consumption/net worth. Borrowing per se is neither good nor bad. A debt ratio $f(t)>0$ raises growth if the productivity of capital exceeds the interest rate (b-r) $>$ 0 . Thus borrowing is productive if $(b-r)>0$, otherwise it reduces growth.

The second set of terms concern the stochastic elements, concerning the return and the interest rate. They may be positively or negatively correlated $E\left[d_{w_{y}} d_{\mathrm{r}}\right]=\rho d t$, where correlation $1>\rho>-1$.

To solve for net worth, start with the Ito equation,

$d \ln X(t)=(1 / X(t)) d X(t)-\left(d X(t)^{2}\right) /\left(2 X(t)^{2}\right)$.

Using the stochastic calculus, Ito equation (See [8]), from (13) derive the basic stochastic differential equation (14). The expected change in net worth $\mathrm{E} d \ln \mathrm{X}(\mathrm{t})$ is (15), which is abbreviated as (15a).

$$
\begin{aligned}
& d \ln X(t)=[(b-c)+(b-r) f(t)] d t+\left[\sigma_{y}(1+f(t)) d w_{y}-\sigma_{r} f(t) d w_{r}\right] \\
& -(1 / 2)\left[\sigma_{y}^{2}(1+f(t))^{2}+\sigma_{r}^{2} f(t)^{2}-2 \sigma_{r} \sigma_{y} f(t)(1+f(t)) \rho\right] d t \ldots \\
& E[d \quad \ln \quad X(t)] \quad(14) \\
& (1 / 2)\left[\sigma_{y}^{2}(1+f(t))^{2}+\sigma_{r}^{2} f(t)^{2}-2 \sigma_{r} \sigma_{y} f(t)(1+f(t)) \rho\right] d t \ldots \\
& d \ln X(t)=M[f(t)]-(1 / 2) Q[f(t)] \ldots \\
& M[f(t)]=[(b-c)+(b-r) f(t)] d t \\
& Q[f(t)]=\left[\sigma_{y}^{2}(1+f(t))^{2}+\sigma_{r}^{2} f(t)^{2}-2 \sigma_{r} \sigma_{y} f(t)(1+f(t)) \rho\right] d t .
\end{aligned}
$$

These two terms are graphed in Fig. (4). The straight line is $\mathrm{M}[\mathrm{f}(\mathrm{t})]$ called the mean. The intercept is (b-c) the mean productivity of capital less the constant consumption ratio. The slope is (b-r), the mean productivity of capital less the interest rate. If there were no debt, then the expected growth of net worth is (b-c). A higher consumption ratio than the productivity of capital reduces growth. Fig. (4) describes the case where $(b-c)>0$ and $(b-r)>0$.

The stochastic terms $\mathrm{Q}[\mathrm{f}(\mathrm{t})]$ are described by the quadratic called risk. The minimum risk debt ratio is $\mathrm{f}(0)$. For values of the debt ratio less than f-max, the Mean exceeds the Risk. 
The optimal debt ratio is equation (16). It is the ratio $f^{*}(t)$ where the difference between the line Mean and quadratic is maximal. It is abbreviated as (16a).

$f^{*}(t)=\operatorname{argmax}[M(f(t)]-(1 / 2) Q(f(t))]=\left[(b-r)-\left(\sigma_{y}-\right.\right.$ $\left.\left.\rho \sigma_{r} \sigma_{y}\right)\right] / \sigma^{2} \ldots$

$f^{*}(t)=[(b-r)] / \sigma^{2}-f(0) \ldots$

$\sigma^{2}=\sigma_{y}^{2}+\sigma_{r}^{2}-2 \rho \sigma_{r} \sigma_{y}$.

From Fig. (4), it is seen that as the debt ratio $f(t)$ exceeds the optimal $f^{*}(t)$, the expected growth declines and the risk rises. If the debt ratio $f(t)$ exceeds $f$-max, the expected growth is negative. Therefore an "excessive" debt is one which exceeds the optimal ratio and the probability of a debt crisis increases.

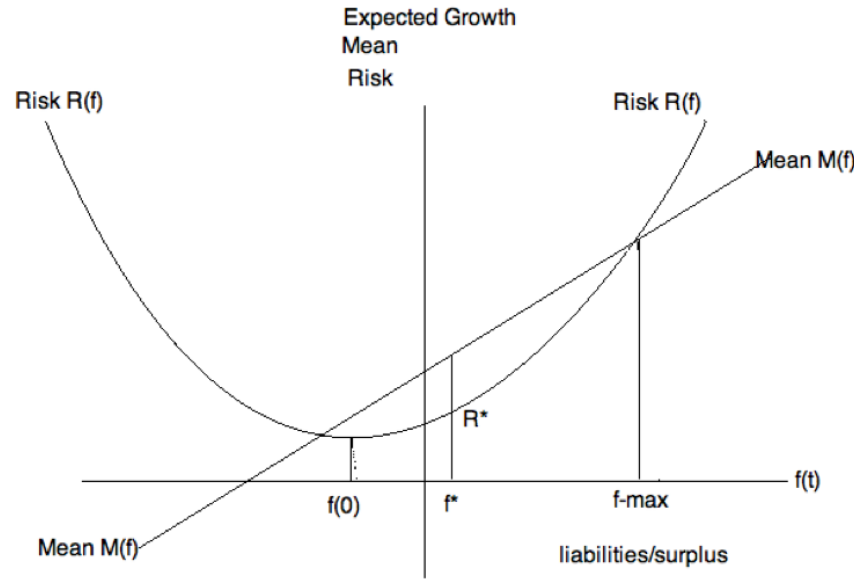

Fig. (4). The debt ratio is debt/net worth or liabilities/surplus. Expected growth of net worth $\mathrm{M}(\mathrm{f})-\mathrm{R}(\mathrm{f})$ is maximal when the debt ratio is $f^{*} . R(f)$ is the same as $Q(f)$.

Stein [3] applied this analysis to the housing market and financial crisis of 2008. He showed that an empirical measure of excess debt, actual $f(t)$ less an estimate of the optimal $f^{*}(t)$ is a good early warning signal of the financial crisis of 2008. There was no significant excess debt from 1980 to 2000. By 2004, the excess debt was two standard deviations above the mean. This should have alerted Washington and Wall Street of an impending crisis.

\section{DETERMINISTIC [MAX(MIN EXPECTED GROWTH)] GAME AGAINST NATURE}

The SOC approach has limitations. Primarily, the Brownian Motion (BM) assumptions in the stochastic processes, equations (11) (12), are questionable. The disturbances are generally not i.i.d. An alternative approach is a differential game against Nature. This approach is based upon Fleming $[14,15]$.

The optimizer has assets which earn income, and liabilties primarily to the creditors, such as the shadow banking system. The identity is: assets/net worth $=1+$ debt/net worth. The optimizer selects a debt/net worth ratio $f$. Nature, knowing the choice, selects a shock/disturbance $v$ that minimizes the expected logarithm of net worth of the optimizer. The constraint is that the greater is the absolute value of the shock, the less likely is it. Therefore, in the minimization, Nature must balance these two aspects of the shock to net worth: harm to the optimizer against its probability. On the basis of the optimum shock $v^{*}$ selected by Nature, the optimizer selects a debt ratio $\mathrm{f}^{*}$ that maximizes the log of the minimum expected net worth. The optimal ratio protects the optimizer from the worst expected shock. Thus the optimal debt ratio $f=$ debt/net worth for the optimizer is: Optimal debt/net worth $\mathrm{f}^{*}=\operatorname{argmax}_{\mathrm{f}} \log \min _{\mathrm{v}}$ $\mathrm{E}(\mathrm{X})$.

\subsection{Model}

The growth of net worth is, as before, equation (10). Instead of stochastic processes (11),(12) we take a deterministic approach, following Fleming [14, 15]. Instead of (11), the key variable is the return $b(t)$. The relevant shock $\mathrm{v}$ is to the return. Positive values raise, and negative values lower, the return. Parameter $a$ indicates the effect of the shock upon the return. For example, it will vary by periods. See Fig. (1) for types of periods. In tranquil periods, $a$ is low and in periods $\mathrm{f}$ financial stress it is high.

$b(t)=b+a v(t), v(t)=$ shock $\quad \infty>v>-\infty \ldots$

Using (17) in (10), the differential equation for net worth is equation (18). The change in the logarithm is (19). Since the model is deterministic, the stochastic calculus is not used. For expositional simplicity, consider the constant controls case: $\mathrm{f}(\mathrm{t})=\mathrm{L} / \mathrm{X}=\mathrm{f}, \mathrm{v}(\mathrm{t})=\mathrm{v}, \mathrm{C}(\mathrm{t})=\mathrm{cX}(\mathrm{t}), \mathrm{r}(\mathrm{t})=\mathrm{r}$. Integrate (18) to derive (19).

$d X / d t=X(t)[(b+a v-c)+(b+a v-r) f(t)] \ldots$

$d \ln X(t) / d t=(1 / X(t)) d X(t) / d t=[(b+a v-c)+(b+a v-$ r) $f(t)] \ldots$

$\log X(t)=[(b+a v-c)+(b+a v-r) f] t+\log X(0)$

$=[(b-c)+(b-r) f+(1+f) a v] t+\log X(0) \ldots$

Both the optimizer and Nature are concerned with the logarithm of expected net worth. In effect, this involves the expectation of the assumed constant shock $\mathrm{v}$ to net worth. In this deterministic model, there is no probability distribution function. Instead, let q be an inverse measure of the liklihood of shock $|\mathrm{v}(\mathrm{t})|$. It looks like, but is not, the inverse normal variable. The liklihood function is equation (21) or (22) for the constant controls case. This is based upon Fleming [14] equation (5.7). As v ${ }^{2}$ rises, the liklihood decreases. Consider for simplicity constant values of the shock $\mathrm{v}$.

$\ln q_{t}(v)=(1 / 2) \int v_{s}^{2} d s=(1 / 2) v^{2} t \ldots 0<s<t$

$q_{t}(v)=\exp \left[(1 / 2) \int v_{s}^{2} d s\right]=\exp \left[(1 / 2) v^{2} t\right] \ldots$

$\mathrm{q}(0)=1$ is a maximum "probability measure"

Instead of Brownian Motion, the "liklihood" variable, the shock v, is chosen by the "minimizer"/stronger player/Nature.

\subsection{Nature's Optimization}

The expected net worth is equation (23), in the constant controls case.

$\log q X==\{\log X(0)+[(b-c)+(b-r) f+(1+f) a v+(1 / 2)$ $\left.\left.v^{2}\right] t\right\} \ldots$

Nature, knowing the debt ratio $f$ selected, chooses a constant control disturbance $\mathrm{v}$ that minimizes the logarithm of expected net worth. This is equation (24), Fleming [15] equation (5.10). 
$\min _{v} \log E(x)=\min _{v} \log q_{t}(v) x(t)=\min _{v}\left\lfloor\log x(t)+(1 / 2) \int v_{s}^{2} d s\right] \ldots$

Consider for simplicity constant values of the shock: $v(t)$ $=\mathrm{v}$ constant. The optimum shock for Nature is $\mathrm{v}^{*}$, the shock that minimizes the expectation of the logarithm of net worth. This is called min-plus expectation [15]. It is not the mean of a probability distribution, but a deterministic concept.

$v^{*}=\operatorname{argmin}_{v} \log q X=\operatorname{argmin}_{v}\left[(1+f) a v+(1 / 2) v^{2}\right]=-a^{2}(1+f), \ldots$

Leverage is defined as the ratio of assts/net worth. Equation (25) states that Nature selects a negative shock to the rate of return that that is minus leverage. The greater the leverage, the greater the negative shock that Nature selects. The maximum expected harm to the optimizer is proportional to the square of leverage. This implies that the minimum of the terms involving Nature is equation (26).

$\min _{v}\left[(1+f) v+(1 / 2) v^{2}\right]=-(1 / 2) a^{2}(1+f)^{2} \ldots$

\subsection{Optimization}

The optimizer therefore selects a debt ratio that maximizes the minimum of the logarithm of expected net worth. This is equation (27), the maximum of the minimum of expected growth of net worth.

$\max _{f} \min _{v} E(X)=\max _{f} \min _{v} \log q X$

$=\max _{f}\left\{\log X(0)+\left[(b-r) f+(b-c)-(1 / 2) a^{2}(1+f)^{2}\right] t\right\} \ldots$

The minimum expected growth, the terms in brackets, is graphed in Fig. (5). Minimum Expected Growth $\Lambda$ (f), equation (28), is a quadratic function of the debt ratio $f$ or of leverage $(1+f)$. It has a maximum at $\mathrm{f}=\mathrm{f}^{*}$, equation (29). At debt ratio f-max, the minimum expected growth is zero, and it is negative for debt ratio greater than f-max. Thus the maximum leverage consistent with positive growth is $1+$ (f$\max )$.

$\Lambda(f)=[E \log x(t)-\log X(0)] / t=[(b-r) f+(b-c)-(1 / 2)$

$\left.a^{2}(1+f)^{2}\right] \ldots$

$\Lambda(0)=(b-c)-(1 / 2) a^{2} \ldots$

$d \Lambda / d f=(b-r)-a^{2}\left(1+f^{*}\right)=0, \Lambda^{\prime \prime}<0$.

$\Lambda(f-\max )=0$ $\left.f^{*}\right)$.

The optimal debt ratio is (29). Optimum leverage is $(1+$

$f^{*}=\operatorname{argmax}\left[(b-r) f-(1 / 2) a^{2}(1+f)^{2}\right]=\left[(b-r) / a^{2}-1\right] \ldots$

The Max min expected growth is (30)

$\Lambda\left(f^{*}\right)=(r-c)+(1 / 2)(b-r)^{2} / a^{2} \quad \ldots$

Therefore, the maximum of the minimum of expected growth is equation (30). It is a linear combination of two terms: the interest rate less the consumption rate $(\mathrm{r}-\mathrm{c})$ and one half of the square of $(b-r)$, the productivity of assets when $\mathrm{v}=0$ less the interest rate.

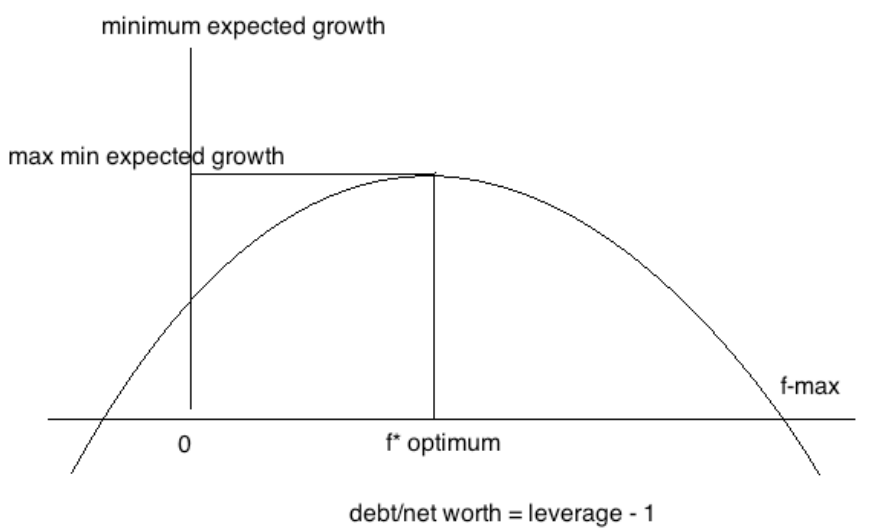

Fig. (5). Minimum Expected Growth $\Lambda(f)$, equation (28), is a quadratic function of the debt ratio. It has a maximum at $\mathrm{f}=\mathrm{f}^{*}$, equation (29). At debt ratio f-max, minimum expected growth is zero.

\section{CONCLUSION}

As a result of the US financial debt crisis of 2008, regulators have focused upon banks and financial intermediaries and asked if they have sufficient net worth to withstand losses. Net worth is assets less liabilities. Leverage is the ratio of assets/net worth equal to $(1+$ debt/net worth $)$. Therefore, the question is whether the debt ratio, or leverage, is too high. One can respond to this question by using the two approaches to optimal debt ratio, summarized in Table 2.

The philosophies of the stochastic optimal control and the differential game against Nature are quite different. However, the same basic conclusion concerning the optimum debt/net worth applies to both. The stochastic optimal control (SOC) approach aims to maximize the expectation of the logarithm of net worth at some later date. This is a risk averse strategy. It requires probability estimates of declines in net worth. Explicit attention is paid to the variabilities and correlations of the diffusion terms. Deficiencies of this approach are that one cannot be too confident that he knows the probability distribution function, that it is constant and that the stochastic terms are i.i.d. The failure of Long Term Capital Management LTCM and the errors of the Quants in the housing price bubble (see [3] chapter 3) stemmed from these erroneous assumptions.

The differential game against Nature is designed to protect the optimizer against the liklihood that a negative shock that will harm net worth. It is a conservative philosophy that attempts to maximize the minimum

Table 2. Summary/Comparison of SOC and Differential game for $f^{*}=$ Optimal Debt/Net Worth

\begin{tabular}{|c|c|c|}
\hline & Stochastic Optimal Control & Differential Game \\
\hline $\begin{array}{l}\text { Optimization } \\
\mathrm{X}=\text { net worth }\end{array}$ & $\operatorname{Max}_{f} E \ln X(T)$ & $\operatorname{Max}_{f} \operatorname{Min}_{v} E[\ln X(T)]$ \\
\hline $\begin{array}{c}\text { Optimal debt/net worth } \mathrm{f}^{*} \\
\text { Leverage }=\text { assets } / \text { net worth }=1+\operatorname{debt} / \text { net worth }\end{array}$ & $\mathrm{f}^{*}=(\mathrm{b}-\mathrm{r}) / \sigma^{2}-\mathrm{f}(0)$ & $\mathrm{f}^{*}=(\mathrm{b}-\mathrm{r}) / a^{2}-1$ \\
\hline $\mathrm{b}=$ productivity of assets, $\mathrm{r}=$ interest rate & $f(0)$ and $\sigma^{2}$ involve variances and covariance's & deterministic \\
\hline
\end{tabular}


expectation of growth or level of net worth. There are no questionable stochastic processes nor Brownian Motion diffusions. The only assumption is that the liklihood of the shock is symmetrical around zero and the large absolute values are less likely than small ones.

The net results concerning the optimal ratio of debt/net worth $f^{*}$ or leverage have similar forms, summarized in Table 2. Both stress that the debt ratio should follow (b-r). Thus if the productivity of assets is falling relative to the interest rate, the debt ratio or leverage should be reduced. The difference is that the SOC approach also stresses that the variabilities of growth and interest rate should reduce the optimal ratio. In both cases, an early warning signal of difficulties is that the debt ratio exceeds $\mathrm{f}^{*}$ the optimal ratio.

\section{ACKNOWLEDGEMENT}

I thank Wendell H. Fleming for his suggestions and sharing his insights into optimal stochastic and deterministic control.

\section{CONFLICT OF INTEREST}

Declared none.

\section{REFERENCES}

[1] Feynman R. The Character of Physical Law. USA: MIT Press 1965.

[2] Derman E. My Life as a Quant. USA: Wiley 2004.

[3] Stein JL. Stochastic optimal control and the US financial crisis. New York: Springer 2012.

[4] Handel A, Margolis E, Levin B. Exploring the role of the immune response in preventing antibiotic resistance. J Theor Biol 2009; 256(4): 655-62.

[5] Stewart F, Levin B. The population biology of bacterial plasmids. Genetics 1977; 87: 1 .

[6] Frank S. Dynamics of Cancer. USA: Princeton University Press 2007.

[7] Braun M. Differential Equations and their applications. USA: Springer-Verlag 1975

[8] Øksendal B. Stochastic Differential Equations. USA: Springer 1995.

[9] Merton R. Continuous time finance. USA: Blackwell 1990.

[10] Fleming W, Raymond R. Deterministic and stochastic optimal control. USA: Springer-Verlag 1975.

[11] Fleming W, Soner HM. Controlled markov processes and viscosity solutions. USA: Springer 2006.

[12] Stein JL. Optimal debt and endogenous growth in models of international finance. Australian Econ Pap 2005; 44(4): 389-413.

[13] Fleming W, Stein JL. Stochastic optimal control, international finance and debt. J Bank Finance 2004; 28: 979-96.

[14] Fleming WH. Optimal investment models with minimum consumption criteria. Australian Econ Pap 2005; 44(4): 1-21.

[15] Fleming WH. Stochastic Control models of optimal investment and consumption. Aportaciones Matematicas 2001; 16: 159-209. 